\title{
Plant Polyphenols and Oxidative Metabolites of the Herbal Alkenylbenzene Methyleugenol Suppress Histone Deacetylase Activity in Human Colon Carcinoma Cells
}

\author{
Isabel Anna Maria Groh, Chen Chen, Claudia Lüske, \\ Alexander Thomas Cartus, and Melanie Esselen \\ Division of Food Chemistry and Toxicology, Department of Chemistry, University of Kaiserslautern, Erwin-Schroedinger-Straße 52, \\ 67663 Kaiserslautern, Germany
}

Correspondence should be addressed to Melanie Esselen; melanie.esselen@chemie.uni-kl.de

Received 25 May 2012; Revised 5 September 2012; Accepted 6 September 2012

Academic Editor: Christel Lamberg-Allardt

Copyright (C) 2013 Isabel Anna Maria Groh et al. This is an open access article distributed under the Creative Commons Attribution License, which permits unrestricted use, distribution, and reproduction in any medium, provided the original work is properly cited.

Evidence has been provided that diet and environmental factors directly influence epigenetic mechanisms associated with cancer development in humans. The inhibition of histone deacetylase (HDAC) activity and the disruption of the HDAC complex have been recognized as a potent strategy for cancer therapy and chemoprevention. In the present study, we investigated whether selected plant constituents affect HDAC activity or HDAC1 protein status in the human colon carcinoma cell line HT29. The polyphenols (-)-epigallocatechin-3-gallate (EGCG) and genistein (GEN) as well as two oxidative methyleugenol (ME) metabolites were shown to inhibit HDAC activity in intact HT29 cells. Concomitantly, a significant decrease of the HDAC1 protein level was observed after incubation with EGCG and GEN, whereas the investigated ME metabolites did not affect HDAC1 protein status. In conclusion, dietary compounds were found to possess promising HDAC-inhibitory properties, contributing to epigenetic alterations in colon tumor cells, which should be taken into account in further risk/benefit assessments of polyphenols and alkenylbenzenes.

\section{Introduction}

Cancer is one of the most causes of death in industrial countries. Especially the genesis of tumors of the gastrointestinal tract seems to depend on genetic predisposition, environmental factors, and diet [1]. Evidence has been provided that these factors directly influence epigenetic mechanisms associated with cancer development in humans. Epigenetic mechanisms comprise modulation in DNA methylation, histone modification, and noncoding RNA [2]. DNA methylation/demethylation and histone modifications are controlled by specific enzymes, such as DNA methyltransferase (DNMT), histone acetyltransferase (HAT), and histone deacetylase (HDAC) $[3,4]$. One of the major posttranslational epigenetic regulations of gene expression is the modulation of histones via acetylation and deacetylation [5]. HDACs belong to the group of zinc-binding metalloenzymes catalyzing the elimination of acetyl groups from histone tails. Deacetylation results in the tighter wrapping of DNA around the histone core leading to chromatin condensation. Based on this cellular event the accessibility of transcription factors and gene expression is decreased. HDACs are involved in several cellular regulation processes such as transcription, cell cycle progressing, gene silencing, cell differentiation, DNAreplication and DNA-damage response $[5,6]$. Up to now, 18 human HDAC enzymes are characterized and classified into four classes: class I HDACs share sequence similarity with the yeast Rpd3 deacetylase; they are ubiquitously expressed and are localized in the nucleus. HDACs of class II are homologous to the yeast Hdal deacetylase and translocate between cytoplasm and nucleus. Class III HDACs are represented by sirtuins, a family of seven HDACs sharing homology with the yeast silent information regulator 2 protein (Sir2). Class IV HDAC11 shares conserved residues with both class I and II 
HDACs [7-9]. Various tumor types mainly overexpressed class I HDACs associated with drug resistance and poor prognosis [10]. HDAC inhibitors have emerged as a promising class of therapeutic drugs used in the therapy of Alzheimer or Parkinson disease and cancer [11-17].

Epidemiological studies indicate that cancer incidence might be significantly modulated by an enhanced dietary intake of polyphenols with fruits and vegetables [18, 19]. Based on the proposed health benefits, polyphenol preparations have gained increasing popularity on the fast expanding market of food supplements. Within the class of polyphenols the major green tea catechin (-)-epigallocatechin-3gallate (EGCG), the stilbene resveratrol (found in grapes and wine), several soy isoflavones and carboxylic acid derivatives such as chlorogenic acid (CGA) or caffeic acid have been extensively reported to affect HDAC activity, and all are implicated with a reduced cancer risk [2, 20-24]. However, bioactive compounds can possess also adverse health effects. Methyleugenol (ME) belongs to the class of alkenylbenzenes and occurs in different plants such as nutmeg, pimento, lemongrass, tarragon, basil, star anise, and fennel [25-27]. It is also used as a flavoring agent in jellies, baked goods, beverages, sweets such us chewing gums or ice cream, and as a fragrance in cosmetic products [28]. There is a high interest in the safety evaluation of the food constituent ME, since it has been classified as a genotoxic carcinogen by the Scientific Committee on Food (SCF) [29].

In this study we addressed the question whether the polyphenols chlorogenic acid (CGA), genistein (GEN), and EGCG (Figure 1) inhibit HDAC1 expression and/or HDAC activity in intact human colon carcinoma cells. Furthermore, we include the genotoxic carcinogen $\mathrm{ME}$ and its respective oxidative metabolites $1^{\prime}$-hydroxymethyleugenol (1'-OH-ME), methyleugenol- $2^{\prime}, 3^{\prime}$-epoxide (MEE), and $3^{\prime}$ oxomethylisoeugenol ( $3^{\prime}$-OXO-MIE) (Figure 1) in our testing to get a deeper understanding in mechanisms of action of potential chemopreventive food constituents in comparison to compounds with known adverse health effects.

\section{Materials and Methods}

2.1. Chemicals. Dimethyl sulfoxide (DMSO), ME, CGA, and catalase were purchased from Sigma-Aldrich (Steinheim, Germany). GEN and EGCG were purchased from Extrasynthese (Genay Cedex, France). The methyleugenol metabolites $1^{\prime}$-OH-ME, 3'-OXO-MIE, and MEE were synthesized and purified according to the procedures previously described by our lab [30]. Purities of ME metabolites: $1^{\prime}-\mathrm{OH}-\mathrm{ME}>99.5 \%$; MEE $>99.0 \% ; 3^{\prime}-\mathrm{OXO}-\mathrm{MIE}>97.5 \%$ (with about $2.0 \%$ veratraldehyde), were all checked by $1 \mathrm{H}-\mathrm{NMR}$ and HPLC. All other chemicals were of the highest or reasonably highest purity commercially available.

2.2. Cell Culture. HT29 cells, a human colon adenocarcinoma cell line (Accession number ACC 299, Deutsche Sammlung von Mikroorganismen und Zellkultur (DSMZ), Braunschweig, Germany), were grown in Dulbecco's modified Eagle's medium (DMEM) high glucose $(4.5 \mathrm{~g} / \mathrm{L}$, Invitrogen Life Technologies, Karlsruhe, Germany). Cell culture medium was supplemented with $10 \%$ fetal calf serum (FCS; PAA, Coelbe, Austria) and 1\% penicillin/streptomycin (Invitrogen Life Technologies, Karlsruhe, Germany). Cells were cultured at $37^{\circ} \mathrm{C}$ in a water-saturated atmosphere containing $5 \% \mathrm{CO}_{2}$. Compounds were dissolved in DMSO and added to the medium to yield a final DMSO concentration of $0.5 \%$ $(\mathrm{v} / \mathrm{v})$. Control experiments were carried out with medium containing $0.5 \%$ of DMSO without test compounds.

2.3. Sulforhodamine B Assay. 30,000 (24h), 20,000 (48h), or 8,000 (72h) HT29 cells per well were seeded into 24well plates and allowed to grow for $24 \mathrm{~h}$ before treatment. Thereafter, cells were incubated with the respective test compound for $24 \mathrm{~h}, 48 \mathrm{~h}$, or $72 \mathrm{~h}$ in culture medium. Effects on cell growth were determined according to the general method of Skehan et al. [31] modified according to Kern et al. [32]. Incubation was stopped by addition of trichloroacetic acid ( $50 \%$ solution). The fixed cells were stained with a $0.4 \%$ solution of sulforhodamine B. The dye was eluted with Trisbuffer (10 mM, pH 10.0) and quantified spectrophotometrically at $\lambda=570 \mathrm{~nm}$. Cell growth was measured as percent survival, determined by the number of treated cells over control cells $\times 100(\% \mathrm{~T} / \mathrm{C})$.

2.4. WST-1 Assay. The WST-1 (water soluble tetrazolium) cell proliferation assay was performed according to the manufactures protocol (Roche Diagnostics $\mathrm{GmbH}$, Mannheim, Germany). 5,000 or 3,500 HT29 cells per well, respectively, were seeded into 96-well plates and allowed to grow for $24 \mathrm{~h}$. V79 cells were treated with CGA, EGCG, or GEN for $24 \mathrm{~h}$ or $48 \mathrm{~h}$ under FCS-containing conditions in the presence of catalase $(100 \mathrm{U} / \mathrm{mL})$. In each experiment a solvent control (DMSO 0.5\%) and a positive control IGPAL-CA630 $(0.5 \%)$ were included. After treatment, medium was removed, cells were rinsed with $100 \mu \mathrm{L} /$ well PBS buffer, and then $100 \mu \mathrm{L} /$ well serum-free medium was added. $10 \mu \mathrm{L} /$ well of cell proliferation reagent WST-1 was added to the cells. After $3 \mathrm{~h}$ absorbance was measured at $\lambda=450 \mathrm{~nm}$.

2.5. HDAC Enzyme Activity. HDAC enzyme activity was determined using HDAC Assay Kit obtained from Cayman Chemical Company (Ann Arbor, MI, USA) according to the manufactures protocol. 5,000 HT29 cells per well were seeded in $100 \mu \mathrm{L}$ culture medium in black, clear bottomed 96-well plates. Cells were incubated with CGA, GEN, or EGCG in the presence of catalase to avoid hydrogen peroxide formation, or with $\mathrm{ME}$ and its oxidative metabolites at the respective concentrations. After $24 \mathrm{~h}$ the plate was centrifuged at $500 \times \mathrm{g}$ for 5 minutes and the culture medium was aspirated. $200 \mu \mathrm{L}$ of diluted Assay Buffer (kit constituent) was added to each well, the plate was centrifuged at $500 \times \mathrm{g}$ for 5 minutes, and the supernatant was aspirated. Thereafter, $90 \mu \mathrm{L}$ of culture medium or positive control (recombinant HDAC1) was added to noninhibited sample wells, and $80 \mu \mathrm{L}$ culture medium with $10 \mu \mathrm{L}$ trichostatin A was added to the inhibited samples, respectively. The HDAC reaction was initiated by adding $10 \mu \mathrm{L}$ of the diluted HDAC substrate (BOC- $N^{\varepsilon}$ acetyl-L-lysine-7-amino-4-methylcoumarin) to each well. The plate was incubated for three hours at $37^{\circ} \mathrm{C}$. Cells were 
<smiles>O=C(O[C@H]1Cc2c(O)cc(O)cc2O[C@@H]1c1cc(O)c(O)c(O)c1)c1cc(O)c(O)c(O)c1</smiles>

(-)-Epigallocatechin-3-gallate (EGCG)

$$
\mathrm{HO}
$$<smiles>Cc1cc(O)c2c(=O)c(-c3ccc(O)cc3)coc2c1</smiles>

Genistein (GEN)<smiles>O=C(/C=C/c1ccc(O)c(O)c1)O[C@H]1CC(O)(C(=O)O)C[C@H](O)C1O</smiles>

Chlorogenic acid (CGA)<smiles>CC(/C=C/C(=O)NO)=C\C(C)C(=O)c1ccc(N(C)C)cc1</smiles>

Methyleugenol and metabolites<smiles>C=CCc1ccc(OC)c(OC)c1</smiles>

Methyleugenol (ME)<smiles>C=CC(O)c1ccc(OC)c(OC)c1</smiles>

$1^{\prime}$-Hydroxymethyleugenol (1'-OH-ME)<smiles>COc1ccc(/C=C/C=O)cc1OC</smiles>

3'-Oxomethylisoeugenol (3'-OXO-MIE)<smiles>COc1ccc(CC2CO2)cc1OC</smiles>

Methyleugenol-2' $3^{\prime}$-epoxide (MEE)

FIGURE 1: Food-derived polyphenols of different classes and structure of methyleugenol and selected oxidative metabolites.

lysed by the addition of $50 \mu \mathrm{L}$ Lysis/Developer Mixture (kit constituent) and the plate was shaken for 2 minutes. After an incubation period for 15 minutes at $37^{\circ} \mathrm{C}$ fluorescence was measured at an excitation wavelength of $\lambda_{\text {ex }}=340-$ $360 \mathrm{~nm}$ and an emission wavelength of $\lambda_{\mathrm{em}}=440-465 \mathrm{~nm}$. A deacetylated standard (kit constituent) was used to prepare a standard curve for the quantification of HDAC activity.

2.6. Western Blot Analysis. $4.5 \times 10^{6}$ HT29 cells per Petri dish were seeded in culture medium and allowed to grow for $48 \mathrm{~h}$. Cells were incubated with CGA, GEN, and EGCG in the presence of catalase (see above), or with ME and its oxidative metabolites at respective concentrations. After $24 \mathrm{~h}$ of incubation the culture medium was removed and the cells were washed with ice-cold phosphate buffered saline (PBS) for two times and abraded on ice with $200 \mu \mathrm{L}$ RIPA buffer (65 mM Tris, $154 \mathrm{mM} \mathrm{NaCl}, 1 \mathrm{mM}$ EDTA, $1 \%$ IGEPAL-CA630, pH 7.4). Thereafter the lysate was mixed for 1 minute and was centrifuged for $10 \mathrm{~min}(20,000 \times \mathrm{g}$, $\left.4^{\circ} \mathrm{C}\right)$. The supernatant was separated by SDS-PAGE (12\% polyacrylamide gel) and the proteins were transferred onto a nitrocellulose membrane. Western blot analysis was performed using a goat polyclonal antibody against human HDAC1 (Santa Cruz, Heidelberg, Germany) and an anti-goat IgG-HRP conjugated secondary antibody (Santa Cruz, Heidelberg, Germany). Alpha-tubulin was used as a loading control. The respective chemoluminescent signals (LumiGLO, Santa Cruz, Heidelberg, Germany) were analyzed using a LUMI-IMAGER (Roche, Mannheim, Germany). Arbitrary light units were plotted as test over control [\%]. 


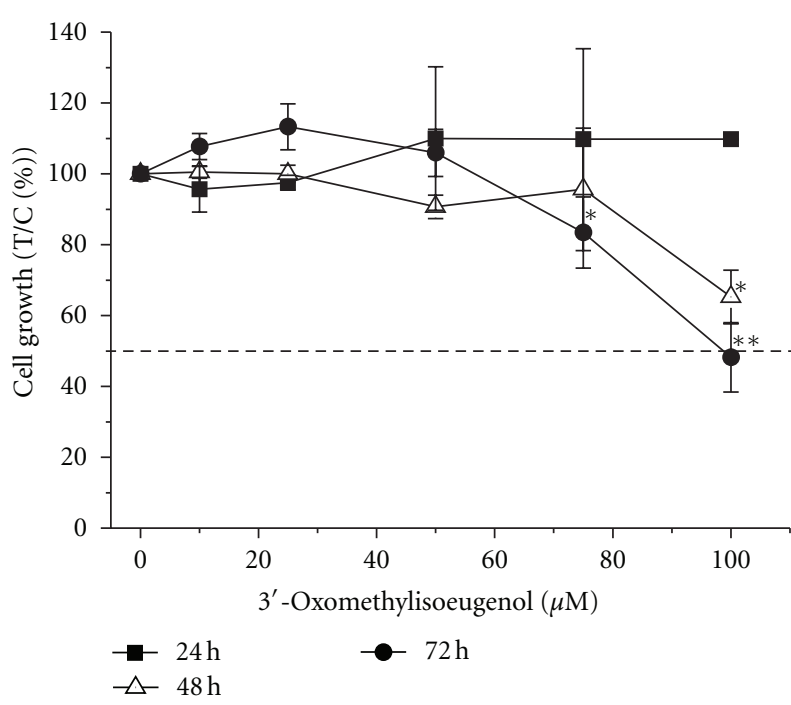

(a)

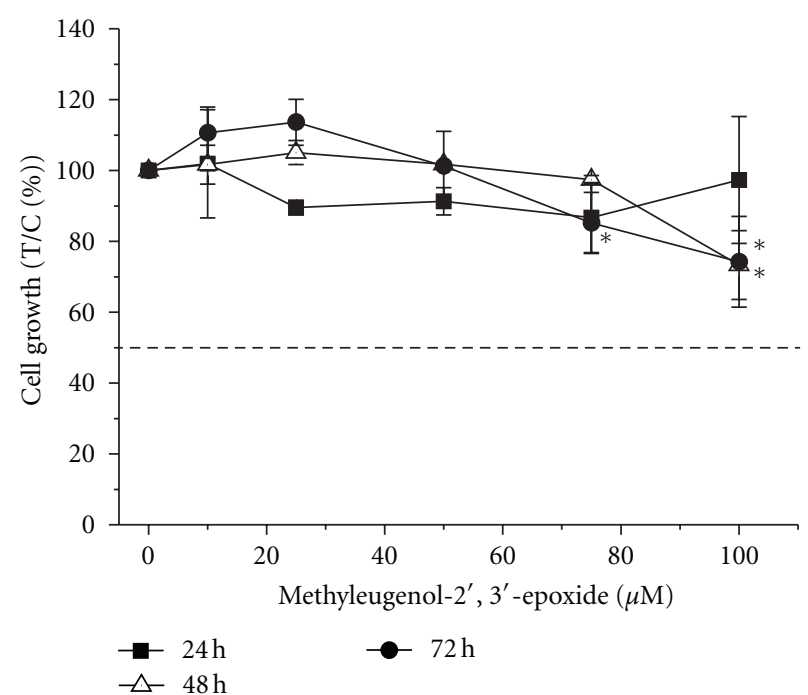

(b)

FIgure 2: Inhibition of tumor cell growth in vitro by (a) $3^{\prime}$-oxomethylisoeugenol ( $3^{\prime}$-OXO-ME) and (b) methyleugenol-2' $3^{\prime}$-epoxide (MEE). Growth inhibition was determined using the sulforhodamine B assay according to Kern et al. [32]. HT29 cells were incubated with the respective compound for $24-72 \mathrm{~h}$. Growth inhibition was calculated as survival of treated cells over control cells (treated with the vehicle $0.5 \% \mathrm{DMSO}) \times 100[\mathrm{~T} / \mathrm{C} \%$ ]. The values given are mean $\pm \mathrm{SD}$ (standard deviation) of at least four independent experiments, each performed in quadruplicate. The significances indicated were calculated in relation to the solvent control DMSO $0.5 \% \mathrm{v} / \mathrm{v}$ (Student's $t$-test: ${ }^{*} P \leq 0.05$; $\left.{ }^{* *} P \leq 0.01\right)$.

\section{Results and Discussion}

\subsection{Results}

3.1.1. Cell Growth Inhibition. Growth inhibitory properties of methyleugenol and selected methyleugenol metabolites in HT29 cells were determined using the sulforhodamine B (SRB) assay over $72 \mathrm{~h}$. No growth inhibitory properties were observed for $\mathrm{ME}$ and $1^{\prime}-\mathrm{OH}-\mathrm{ME}$ using concentrations up to $100 \mu \mathrm{M}$ and $72 \mathrm{~h}$ of incubation (Table 1 ). Whereas $3^{\prime}$ OXO-MIE reduced cell growth in a time and concentrationdependent manner (Figure 2(a)) with a 50\% inhibitory concentration $\left(\mathrm{IC}_{50}\right.$-value) of $100 \pm 14 \mu \mathrm{M}(72 \mathrm{~h}$, Table 1$)$. The oxidative metabolite MEE was found to possess significant growth inhibitory properties without reaching an $\mathrm{IC}_{50}$-value (Figure 2(b), Table 1). Thus, growth inhibitory potency of the investigated alkenylbenzenes in HT29 cells ranked as follows: $3^{\prime}-\mathrm{OXO}-\mathrm{MIE}>\mathrm{MEE}>1^{\prime}-\mathrm{OH}-\mathrm{ME} \approx \mathrm{ME}$.

Cytotoxicity of CGA, GEN, and EGCG was determined in the presence of catalase $(100 \mathrm{U} / \mathrm{mL})$ to avoid hydrogen peroxide formation after an incubation period of $24 \mathrm{~h}$ or $48 \mathrm{~h}$ using the WST 1 (water soluble tetrazolium salt) assay. CGA, GEN, and EGCG did not exhibit cytotoxic effects up to the highest concentration implemented in our further investigations on HDAC expression and activity (data not shown).

3.1.2. Modulation of HDAC Activity. To address the question whether polyphenols or $\mathrm{ME}$ and its respective metabolites modulate HDAC activity in intact cells, HT29 cells were incubated with the test compounds for $24 \mathrm{~h}$ and enzyme
TABLE 1: Cytotoxic properties of the test compounds in HT29 cells.

\begin{tabular}{|c|c|c|c|}
\hline \multirow{2}{*}{ Compound } & \multicolumn{3}{|c|}{$\mathrm{IC}_{50}$-value $[\mu \mathrm{M}]$} \\
\hline & $24 \mathrm{~h}$ & $48 \mathrm{~h}$ & $72 \mathrm{~h}$ \\
\hline EGCG & n.d. ${ }^{\text {a, b }}$ & n.d. ${ }^{\text {a, b }}$ & $40 \pm 6^{c}$ \\
\hline GEN & n.d. ${ }^{a, b}$ & $>100^{\mathrm{b}}$ & $\sim 50^{\mathrm{d}}$ \\
\hline CGA & n.d. ${ }^{a, b}$ & n.d. ${ }^{a, b}$ & $205 \pm 53^{c}$ \\
\hline ME & n.d. ${ }^{\mathrm{a}}$ & n.d. ${ }^{a}$ & n.d. ${ }^{a}$ \\
\hline $1^{\prime}-\mathrm{OH}-\mathrm{ME}$ & n.d. ${ }^{a}$ & n.d. ${ }^{\mathrm{a}}$ & n.d. ${ }^{a}$ \\
\hline $3^{\prime}$-OXO-MIE & n.d. ${ }^{\mathrm{a}}$ & $>100$ & $100 \pm 14$ \\
\hline MEE & n.d. ${ }^{\mathrm{a}}$ & $>100$ & $>100$ \\
\hline
\end{tabular}

a No cytotoxicity up to the highest concentration implemented in the testing; ${ }^{b}$ data was performed in the presence of catalase $(100 \mathrm{U} / \mathrm{mL})$ to avoid hydrogen peroxide formation; ${ }^{\mathrm{c}}$ without catalase; previously reported by Kern et al. [32]; ${ }^{\mathrm{d}}$ previously reported by Yu et al. [33].

activity was determined in an HDAC cell-based activity assay kit. The specific HDAC inhibitor trichostatin A (Figure 1) was used as a positive control ( $80 \%$ inhibition at $2 \mu \mathrm{M}$, Figures 3(a) and 3(b)). EGCG and GEN showed inhibitory effects on cellular HDAC activity in a concentration-dependent manner (Figure 3(a)). The soy isoflavone GEN diminished enzyme activity with an $\mathrm{IC}_{50}$-value of $97 \pm 18 \mu \mathrm{M}$. The green tea catechin EGCG inhibited HDAC activity by about $50 \%$ at $100 \mu \mathrm{M}$. In contrast, CGA exhibited no statistical significant effect on cellular HDAC activity in HT29 cells up to $250 \mu \mathrm{M}$ (Figure 3(a)).

Within the group of alkenylbenzenes $\mathrm{ME}$ and $\mathrm{1}^{\prime}-\mathrm{OH}-\mathrm{ME}$ did not affect HDAC activity up to $100 \mu \mathrm{M}$ (Figure 3(b)). 


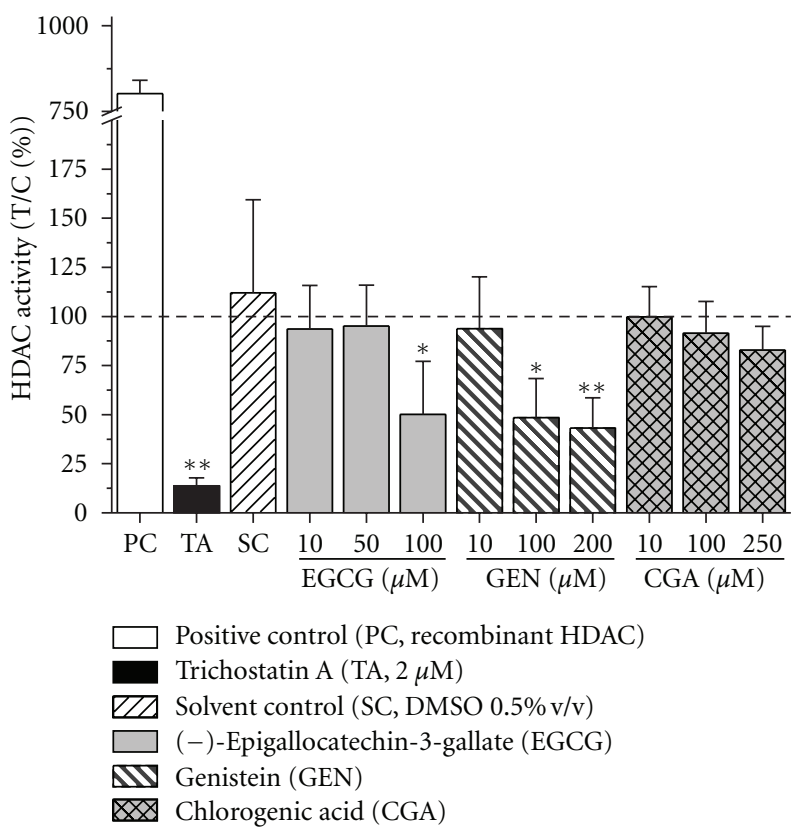

(a)
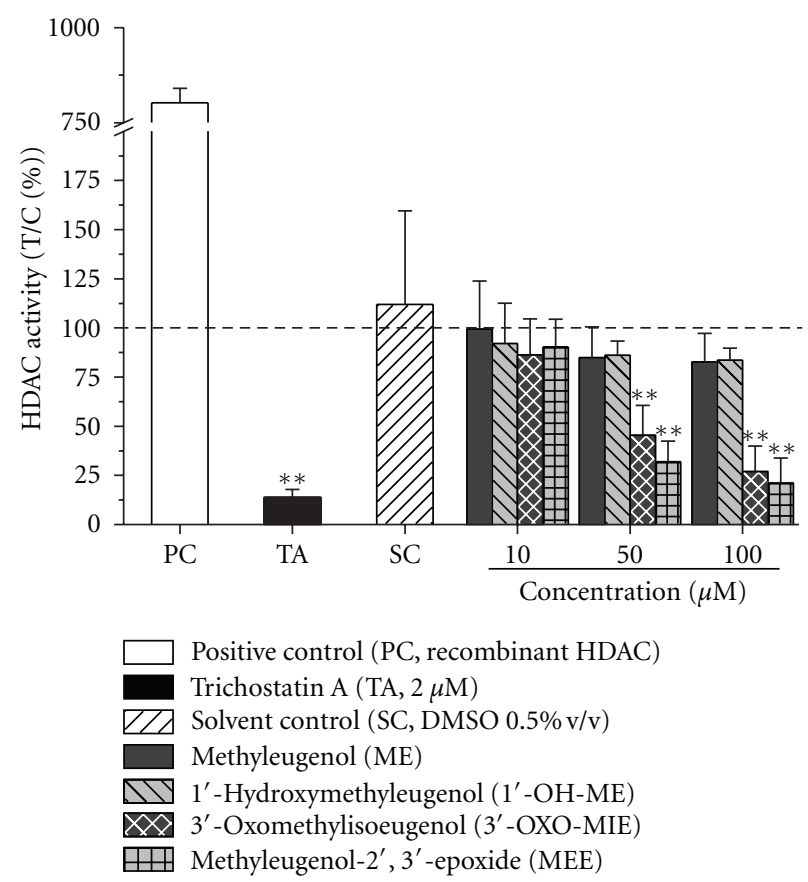

(b)

FIGURE 3: Inhibition of HDAC1 activity in HT29 cells after $24 \mathrm{~h}$ of incubation with (a) polyphenols in the presence of catalase (100 U/mL) or (b) methyleugenol and methyleugenol metabolites. HDAC activity was determined by the metabolic rate of a specific HDAC1 substrate. Recombinant HDACl was included as positive control (PC) and trichostatin A (TA) as a specific HDAC inhibitor. The data presented are mean \pm SD of at least three independent experiments, each performed in a duplicate. The significances indicated were calculated in relation to the solvent control DMSO $0.5 \% \mathrm{v} / \mathrm{v}$ (Student's $t$-test: ${ }^{*} P \leq 0.05 ;{ }^{* *} P \leq 0.01$ ).

However, the ME-derived oxidative metabolites $3^{\prime}$-OXOMIE and MEE significantly inhibited cellular HDAC activity at concentrations $\geq 50 \mu \mathrm{M}$ (Figure $3(\mathrm{~b})$ ), reaching the following IC $_{50}$-values: $54 \pm 20 \mu \mathrm{M}\left(3^{\prime}\right.$-OXO-MIE) and $38 \pm 3 \mu \mathrm{M}$ (MEE), respectively.

3.1.3. Effects on HDAC1 Protein Levels. We further addressed the question whether the modulation of HDAC activity by secondary plant constituents in HT29 cells is associated with changes in the amount of HDAC protein. The impact of the test compounds on HDAC1 protein status in HT29 cells after $24 \mathrm{~h}$ of incubation was detected by western blot analysis using a goat polyclonal antibody against human HDAC1. Incubation of HT29 cells with CGA increased the HDAC1 protein level up to $250 \mu \mathrm{M}$ without statistical relevance (Figures 4(a) and 4(b)). In contrast, the incubation of HT29 cells with GEN resulted in a significant decrease of HDAC1 protein at a concentration of $200 \mu \mathrm{M}$ (Figure 4(a)). EGCG also decreased the protein level of $\mathrm{HDACl}$ in a concentration-dependent manner. The HDAC1 status was significantly reduced at concentrations $\geq 50 \mu \mathrm{M}$ (Figure 4(a)).

After treatment of HT29 cells with methyleugenol or the selected metabolites, no changes in the amount of HDAC1 protein were detected by western blot analysis (Figures 4(c) and $4(\mathrm{~d}))$.
3.2. Discussion. Dietary polyphenols have been demonstrated to exhibit cancer preventive and cancer therapeutic activity [18, 19, 34]. The impact of polyphenols on enzymes involved in cell cycle regulation, apoptosis, invasion, metastasis, and angiogenesis has been associated with their beneficial health effect. More recently, polyphenols have been found to alter gene expression by posttranslational modifications, including DNA methylation or histone acetylation/deacetylation $[8,20,35,36]$. In the present study, EGCG, the most abundant catechin in green tea, was shown to inhibit HDAC activity and HDAC1 protein expression in human colon carcinoma HT29 cells after $24 \mathrm{~h}$ of incubation (Figures 3(a) and 4(a)). Green tea polyphenols and notably EGCG have been reported to diminish HDAC activity, mRNA expression of HDAC1 and protein expression of class I HDACs in prostate cancer cells $[20,21]$. The treatment of LNCaP human prostate cancer cells with EGCG $(5-20 \mu \mathrm{M})$ resulted in a dose- and time-dependent decrease of class I HDACs (HDAC1, 2, 3, and 8) [21]. These results are in line with our findings that incubation with EGCG $(\geq 50 \mu \mathrm{M})$ significantly diminished the protein level of $\mathrm{HDACl}$ in the human carcinoma cell line HT29 (Figures 4(a) and 4(b)), whereas a significant reduction of HDAC activity was also determined but at higher concentrations $(100 \mu \mathrm{M}$, Figure 3(a)). The soy isoflavone GEN significantly inhibited HDAC activity at concentrations $\geq 100 \mu \mathrm{M}$ (Figure 3(a)). 


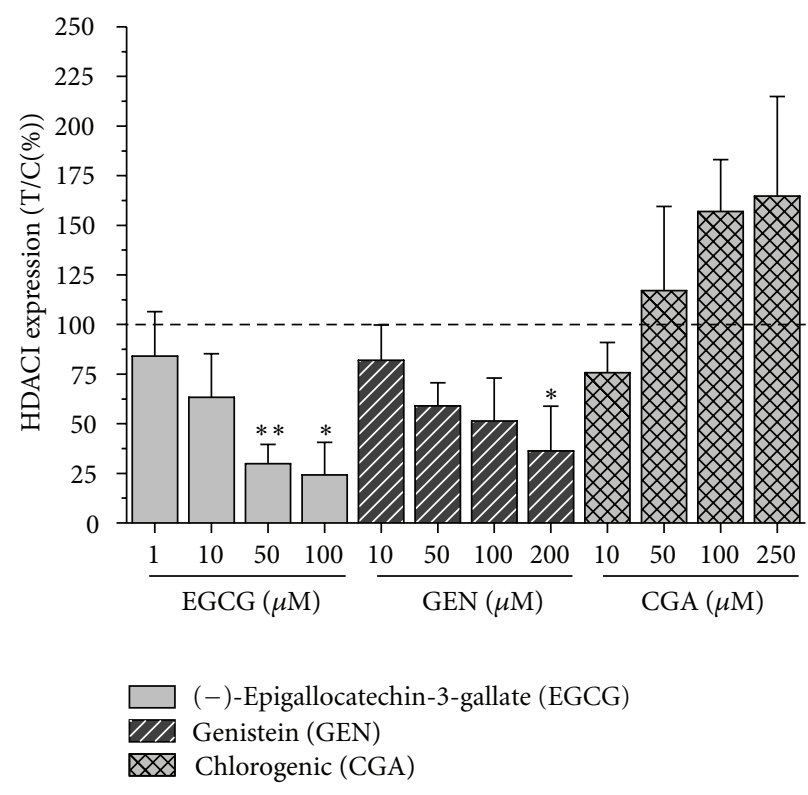

(a)

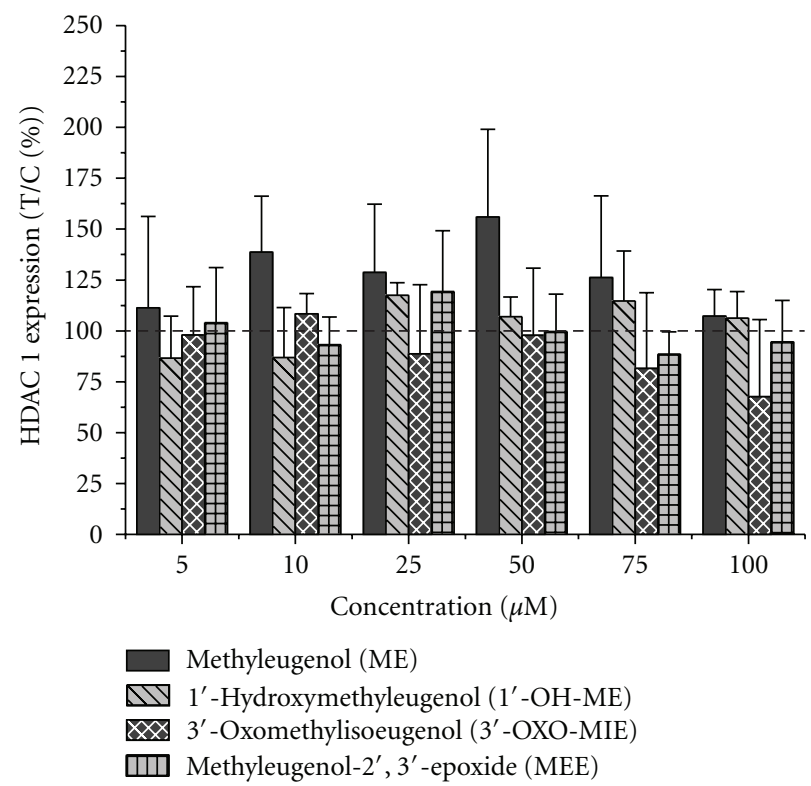

(c)
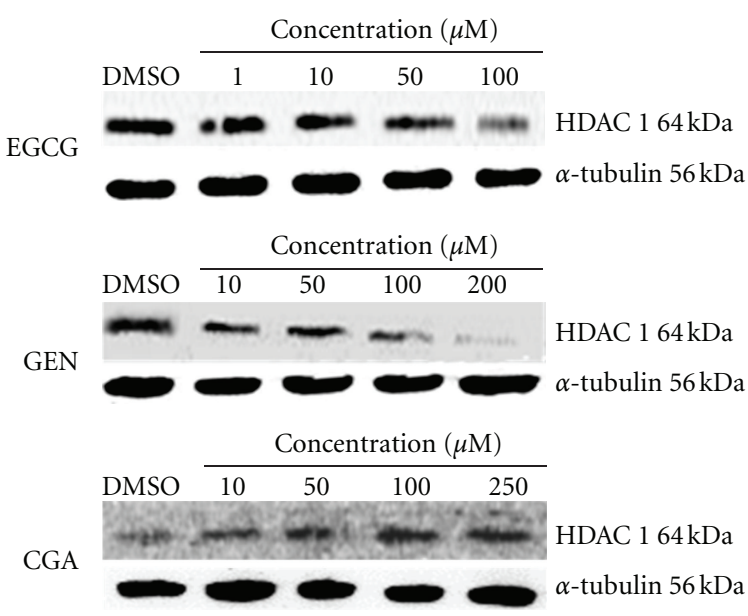

(b)

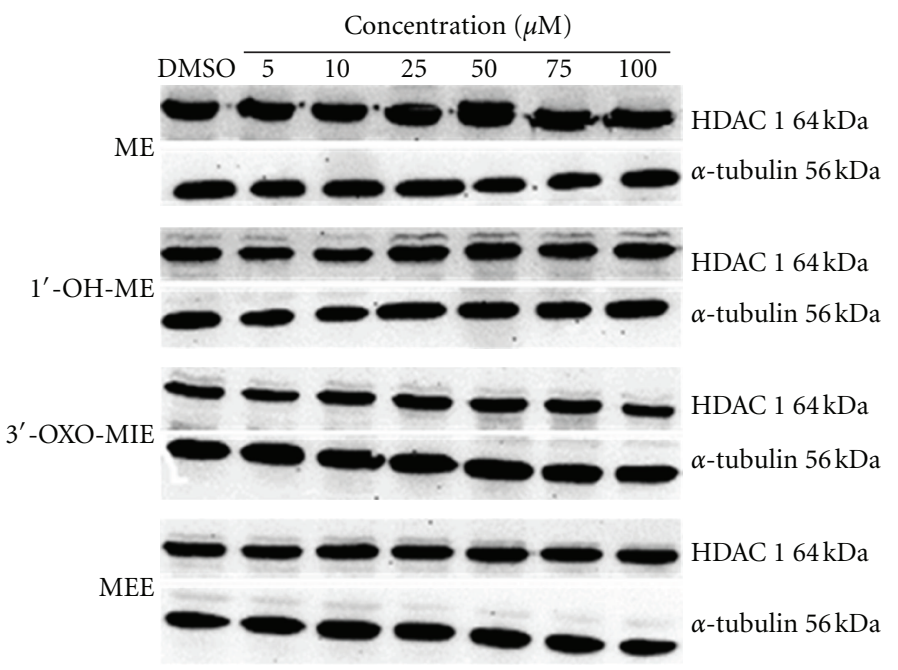

(d)

FIGURE 4: Western blot analysis and representative western blots of HDAC1 expression in HT29 cells after $24 \mathrm{~h}$ treatment with polyphenols in the presence of catalase $(100 \mathrm{U} / \mathrm{mL})((\mathrm{a})$ and $(\mathrm{b}))$ or methyleugenol and respective metabolites ((c) and (d)). DMSO: solvent control (0.5\% $\mathrm{v} / \mathrm{v}), \alpha$-tubulin: loading control. Arbitrary light units were plotted as test over control [\%], with the respective solvent control $(0.5 \% \mathrm{v} / \mathrm{v}$ DMSO) set to $100 \%$. The presented data are mean \pm SD of four independent experiments with similar outcome. The significances indicated were calculated in relation to the lowest applied concentration (Student's $t$-test: ${ }^{*} P \leq 0.05 ;{ }^{* *} P \leq 0.01$ ).

HDAC1 protein expression was significantly reduced after incubation with $200 \mu \mathrm{M}$ GEN (Figures 4(a) and 4(b)). Therefore it can be assumed that other HDAC isoforms are affected by GEN leading to the more pronounced reduction of HDAC activity which needs further investigations. GEN and several other isoflavones have been recently described as HAT activators and HDAC inhibitors in esophageal, prostate, breast, and renal tumor cancer cell lines [24, 3740]. HDAC activity was slightly decreased after the treatment with CGA $(250 \mu \mathrm{M})$, whereas the protein level of HDAC1 was shown to be moderately increased, but both effects were without statistical relevance. HDAC activity of a HeLa nuclear extract was inhibited by CGA with an $\mathrm{IC}_{50}$-value of $375 \mu \mathrm{M}$ [23]. To our knowledge, modulation of HADC 
activity by CGA in cellular systems has not been reported so far. CGA is one major polyphenol of our daily diet, which occurs in several food sources such as apples, potatoes, or coffee [41]. Coffee consumers ingest about $1 \mathrm{~g} / \mathrm{d}$ CGA, whereas a daily intake of chlorogenic acid $<0.1 \mathrm{~g} /$ day has been reported for individuals who do not drink coffee [41, 42]. The average daily intake of soy isoflavones in the western diet has been estimated of about 1-3 mg/day, 30-50 times lower than in Asian countries [43]. A cup of green tea $(200 \mathrm{~mL})$ contains about $150 \mathrm{mg}$ EGCG mainly consumed in Asian countries [44]. Several studies have demonstrated that only a small percentage of ingested GEN, CGA, or EGCG appears in the blood with mean peak plasma concentration levels of nanomolar concentrations [45-47]. Most of the published in vitro investigations, including our study, used the respective polyphenols at micromolar concentrations [20-24]. The rather poor bioavailability of polyphenols needs to be considered when we extrapolate results obtained in vitro to situations in vivo.

Furthermore, it has to be mentioned that cytotoxic effects of the polyphenols EGCG, GEN, and CGA in the implemented concentration range has been intensively discussed $[32,33,48,49]$. Different authors have reported a substantial hydrogen peroxide formation under cell culture conditions, resulting from the reaction of the used polyphenols with yet unknown culture media constituents, which influences the cellular effectiveness of the respective polyphenols [5055]. EGCG exhibited potent growth inhibitory properties, yet in our experiments in accordance with earlier results, the presence of catalase significantly attenuated this effect [55]. The addition of catalase resulted in a loss of any cytotoxic effects of EGCG up to $100 \mu \mathrm{M}$ (data not shown), suggesting that the formation of hydrogen peroxide acts as a major contributor of the reported cytotoxicity. In contrast, no details on hydrogen peroxide formation after cell treatment with GEN have been reported so far. GEN, in the absence of catalase, reduced dose-dependently $(0-100 \mu \mathrm{M})$ the cell viability of HT29 cells after $72 \mathrm{~h}$ of incubation [33], whereas in our experiments no cytotoxicity was measured up to $200 \mu \mathrm{M}$ $(24 \mathrm{~h})$ neither in presence nor in absence of catalase (data not shown).

Taken together, a hydrogen peroxide-scavenging system to in vitro cell culture assays using plant polyphenols seems to be needed. By the use of catalase $(100 \mathrm{U} / \mathrm{mL})$ any artificial contribution of hydrogen peroxide to the inhibitory effects on HDACl protein status and HDAC activity can be excluded.

Within the class of alkenylbenzenes only the two oxidative metabolites $3^{\prime}$-OXO-MIE and MEE observed significant growth inhibitory properties on HT29 cells (Figure 2, Table 1) according to previous results of our group on V79 Chinese hamster lung fibroblasts cells [56]. With respect to the metabolic activity of HT29 cells in contrast to V79 cells we have postulated a variably sensitivity against the test compounds, which was not the case. Furthermore, six oxidative ME-metabolites, including the here-investigated ones, have been reported to reduce cell viability in metabolic competent primary rat hepatocytes by using two different assays. The authors found the highest cytotoxicity for the main ME-metabolite $1^{\prime}$-hydroxymethyleugenol and the secondary metabolite $1^{\prime}$-oxomethyleugenol, whereas ME was found to be much less cytotoxic [57]. These results are in accordance with the studies of Burkey et al. [58], where ME only exhibited marginal cytotoxicity in rat hepatocytes at concentrations up to $3 \mathrm{mM}$.

The levels of HDAC activity within cells can be altered via direct inhibition of the HDAC enzyme and changes in HDAC protein levels. In the study presented here, the metabolites $3^{\prime}$ OXO-MIE and MEE were firstly reported to potently diminish HDAC enzyme activity (Figure 3(b)) without modulating the protein status of HDACl. Further work will be needed to investigate whether the metabolites directly suppress HDAC activity or whether protein expression of the other HDAC isoforms will be suppressed.

HDAC inhibition leads to genomic instability by a variety of mechanisms. This effect may contribute to the cytotoxicity of these drugs. Furthermore, HDAC inhibitors sensitize DNA to exogenous genotoxic damage and induce the generation of reactive oxygen species. At least, HDAC inhibitors could induce chromosome missegregation [59]. Some dietary constituents have been reported to enhance DNA damage and to affect HDAC activity in cancer cells. The glucosinolate sulforaphane induced DNA double strand breaks in the human colon carcinoma cell line HCT116 [8]. Furthermore, HDAC3 and HDAC6 protein expression was decreased by sulforaphane in a time-dependent manner, leading to acetylation of histone $\mathrm{H} 4$ and tubulin, respectively [60]. Within the class of polyphenols EGCG, GEN, and quercetin, a flavonoid found in foods such as citrus fruit, apples, and onions, or resveratrol, has been characterized as HDAC inhibitors with DNA-damaging properties recently reviewed by [8]. We reported previously that $3^{\prime}$-OXO-MIE and MEE significantly induced DNA strand breaks [56]. However, the underlying mechanism of action has been not identified so far. Additional studies are required to elucidate whether downregulation of DNA repair or cell cycle regulating events may be involved in the DNA damaging mechanisms of $3^{\prime}$ OXO-MIE and MEE.

\section{Conclusion}

The present study shows that the polyphenols EGCG and GEN and the two ME metabolites $3^{\prime}$-OXO-MIE and MEE potently diminished the activity of HDAC in intact colon carcinoma cells. We further demonstrated that modulation of HDAC activity is associated with the suppression of HDAC1 protein status by polyphenols, whereas the ME metabolites did not affect the protein level of HDAC1. These results illustrate an interference of EGCG and GEN with epigenetic pathways which may contribute to the idea that dietary polyphenols have potentially chemopreventive effects. Furthermore, we show that via bioactivation of the prominent food carcinogen $\mathrm{ME}$, metabolites not only with potential genotoxic, but also with HDAC inhibitory properties will be generated which may contribute to their DNA-damaging properties. In summary, the results presented reveal that more investigations on the mechanism of action for future 
risk/benefit assessment of polyphenols and alkenylbenzenes will be necessary.

\section{Acknowledgment}

The study was supported by the "Institut Danone Ernährung für Gesundheit e.V."

\section{References}

[1] J. Rafter, M. Govers, P. Martel et al., "PASSCLAIM-diet-related cancer," European Journal of Nutrition, vol. 43, no. 2, pp. II47II84, 2004.

[2] A. Link, F. Balaguer, and A. Goel, "Cancer chemoprevention by dietary polyphenols: promising role for epigenetics," Biochemical Pharmacology, vol. 80, no. 12, pp. 1771-1792, 2010.

[3] A. Shilatifard, "Chromatin modifications by methylation and ubiquitination: implications in the regulation of gene expression," Annual Review of Biochemistry, vol. 75, pp. 243-269, 2006.

[4] L. Sui, Y. Wang, L. H. Ju et al., "Epigenetic regulation of reelin and brain-derived neurotrophic factor genes in long-tern potentiation in rat medial prefrontal cortex," Neurobiology of Learning Memory, vol. 97, no. 4, pp. 425-440, 2012.

[5] P. A. Marks, V. M. Richon, T. Miller, and W. K. Kelly, "Histone deacetylase inhibitors," Advances in Cancer Research, vol. 91, pp. 137-168, 2004.

[6] M. Dokmanovic and P. A. Marks, "Prospects: histone deacetylase inhibitors," Journal of Cellular Biochemistry, vol. 96, no. 2, pp. 293-304, 2005.

[7] L. Gao, M. A. Cueto, F. Asselbergs, and P. Atadja, "Cloning and functional characterization of HDAC11, a novel member of the human histone deacetylase family," Journal of Biological Chemistry, vol. 277, no. 28, pp. 25748-25755, 2002.

[8] P. Rajendran, E. Ho, D. E. Williams et al., "Dietary phytochemicals, HDAC inhibition, and DNA damage/repair defects in cancer cells," Clinical Epigenetics, vol. 3, no. 1, p. 4, 2011.

[9] V. S. Thakur, K. Gupta, and S. Gupta, "Green tea polyphenols causes cell cycle arrest and apoptosis in prostate cancer cells by suppressing class I histone deacetylases," Carcinogenesis, vol. 33, no. 2, pp. 377-384, 2012.

[10] W. Weichert, A. Röske, S. Niesporek et al., "Class I histone deacetylase expression has independent prognostic impact in human colorectal cancer: specific role of class I histone deacetylases in vitro and in vivo," Clinical Cancer Research, vol. 14, no. 6, pp. 1669-1677, 2008.

[11] E. Hahnen, J. Hauke, C. Tränkle et al., "Histone deacetlyase ihhibitors: possible implications for neurodegenerative disorders," Expert Opinion on Investigational Drugs, vol. 17, pp. 169184, 2008.

[12] B. E. Morrison, N. Majdzadeh, and S. R. D’Mello, "Histone deacetylases: focus on the nervous system," Cellular and Molecular Life Sciences, vol. 64, no. 17, pp. 2258-2269, 2007.

[13] D. M. Chuang, Y. Leng, Z. Marinova, H. J. Kim, and C. T. Chiu, "Multiple roles of HDAC inhibition in neurodegenerative conditions," Trends in Neurosciences, vol. 32, no. 11, pp. 591-601, 2009.

[14] T. Abel and R. S. Zukin, "Epigenetic targets of HDAC inhibition in neurodegenerative and psychiatric disorders," Current Opinion in Pharmacology, vol. 8, no. 1, pp. 57-64, 2008.
[15] O. Moradei, C. R. Maroun, I. Paquin, and A. Vaisburg, "Histone deacetylase inhibitors: latest developments, trends and prospects," Current Medicinal Chemistry, vol. 5, no. 5, pp. 529560, 2005.

[16] W. S. Xu, R. B. Parmigiani, and P. A. Marks, "Histone deacetylase inhibitors: molecular mechanisms of action," Oncogene, vol. 26, no. 37, pp. 5541-5552, 2007.

[17] M. Jung, "Inhibitors of histone deacetylase as new anticancer agents," Current Medicinal Chemistry, vol. 8, no. 12, pp. 15051511, 2001.

[18] G. G. Duthie, S. J. Duthie, and J. A. M. Kyle, "Plant polyphenols in cancer and heart disease: implications as nutritional antioxidants," Nutrition Research Reviews, vol. 13, no. 1, pp. 79-106, 2000.

[19] C. S. Yang, J. M. Landau, M. T. Huang, and H. L. Newmark, "Inhibition of carcinogenesis by dietary polyphenolic compounds," Annual Review of Nutrition, vol. 21, pp. 381-406, 2001.

[20] M. Pandey, S. Shukla, and S. Gupta, "Promoter demethylation and chromatin remodeling by green tea polyphenols leads to re-expression of GSTP1 in human prostate cancer cells," International Journal of Cancer, vol. 126, no. 11, pp. 2520-2533, 2010.

[21] V. S. Thakur, K. Gupta, and S. Gupta, "Green tea polyphenols increased p53 transcriptional activity and acetylation by suppressing class I histone deacetylase," International Journal of Oncology, vol. 41, no. 1, pp. 353-361, 2012.

[22] M. Waldecker, T. Kautenburger, H. Daumann, C. Busch, and D. Schrenk, "Inhibition of histone-deacetylase activity by shortchain fatty acids and some polyphenol metabolites formed in the colon," Journal of Nutritional Biochemistry, vol. 19, no. 9, pp. 587-593, 2008.

[23] H. L. Liu, Y. Chen, G. H. Cui, and J. F. Zhou, "Curcumin, a potent anti-tumor reagent, is a novel histone deacetylase inhibitor regulating B-NHL cell line Raji proliferation," Acta Pharmacologica Sinica, vol. 26, no. 5, pp. 603-609, 2005.

[24] N. Kikuno, H. Shiina, S. Urakami et al., "Genistein mediated histone acetylation and demethylation activates tumor suppressor genes in prostate cancer cells," International Journal of Cancer, vol. 123, no. 3, pp. 552-560, 2008.

[25] I. Gardner, H. Wakazono, P. Bergin et al., "Cytochrome P450 mediated bioactivation of methyleugenol to 1'-hydroxymethyleugenol in Fischer 344 rat and human liver microsomes," Carcinogenesis, vol. 18, no. 9, pp. 1775-1783, 1997.

[26] S. M. F. Jeurissen, J. J. P. Bogaards, M. G. Boersma et al., "Human cytochrome P450 enzymes of importance for the bioactivation of methyleugenol to the proximate carcinogen $1^{\prime}$ hydroxymethyleugenol," Chemical Research in Toxicology, vol. 19, no. 1, pp. 111-116, 2006.

[27] National Toxicology Program (NTP), “Toxicology and cancinogenesis studies of methyleugenol in $\mathrm{F} 344 / \mathrm{N}$ rats and $\mathrm{B} 6 \mathrm{C} 3 \mathrm{~F} 1$ mice (gavage studies)," DRAFT NTP-TR-491 98-3950, NIH, 2000.

[28] R. L. Smith, T. B. Adams, J. Doull et al., "Safety assessment of allylalkoxybenzene derivatives used as flavouring substancesmethyl eugenol and estragole," Food and Chemical Toxicology, vol. 40, no. 7, pp. 851-870, 2002.

[29] Scientific Committee of Food (SCF), "Opinion of the Scientific Committee of Food on Methyleugenol (4-Allyl-1, 2- dimethoxybenzene)," 2001. 
[30] A. T. Cartus, K.-H. Merz, and D. Schrenk, "Metabolism of methylisoeugenol in liver microsomes of human, rat, and bovine origin," Drug Metabolism and Disposition, vol. 39, no. 9, pp. 1727-1733, 2011.

[31] P. Skehan, R. Storeng, D. Scudiero et al., "New colorimetric cytotoxicity assay for anticancer-drug screening," Journal of the National Cancer Institute, vol. 82, no. 13, pp. 1107-1112, 1990.

[32] M. Kern, Z. Tjaden, Y. Ngiewih et al., "Inhibitors of the epidermal growth factor receptor in apple juice extract," Molecular Nutrition \& Food Research, vol. 49, no. 4, pp. 317-328, 2005.

[33] Z. Yu, W. Li, and F. Liu, "Inhibition of proliferation and induction of apoptosis by genistein in colon cancer HT-29 cells," Cancer Letters, vol. 215, no. 2, pp. 159-166, 2004.

[34] D. Chen and Q. Ping Dou, "Tea polyphenols and their roles in cancer prevention and chemotherapy," International Journal of Molecular Sciences, vol. 9, no. 7, pp. 1196-1206, 2008.

[35] V. Nandakumar, M. Vaid, and S. K. Katiyar, “(-)-Epigallocatechin-3-gallate reactivates silenced tumor suppressor genes, Cip1/p21 and p16INK4a, by reducing DNA methylation and increasing histones acetylation in human skin cancer cells," Carcinogenesis, vol. 32, no. 4, pp. 537-544, 2011.

[36] S. I. Khan, P. Aumsuwan, I. A. Khan, L. A. Walker, and A. K. Dasmahapatra, "Epigenetic events associated with breast cancer and their prevention by dietary components targeting the epigenome," Chemical Research in Toxicology, vol. 25, no. 1, pp. 61-73, 2012.

[37] M. Z. Fang, D. Chen, Y. Sun, Z. Jin, J. K. Christman, and C. S. Yang, "Reversal of hypermethylation and reactivation of p16INK4a, RARbeta, and MGMT genes by genistein and other isoflavones from soy," Clinical Cancer Research, vol. 11, no. 19, pp. 7033-7041, 2005.

[38] Y. Li, L. Liu, L. G. Andrews, and T. O. Tollefsbol, "Genistein depletes telomerase activity through cross-talk between genetic and epigenetic mechanisms," International Journal of Cancer, vol. 125, no. 2, pp. 286-296, 2009.

[39] S. Majid, A. A. Dar, A. E. Ahmad et al., "BTG3 tumor suppressor gene promoter demethylation, histone modification and cell cycle arrest by genistein in renal cancer," Carcinogenesis, vol. 30, no. 4, pp. 662-670, 2009.

[40] T. Hong, T. Nakagawa, W. Pan et al., "Isoflavones stimulate estrogen receptor-mediated core histone acetylation," Biochemical and Biophysical Research Communications, vol. 317, no. 1, pp. 259-264, 2004.

[41] M. N. Clifford, "Chlorogenic acids and other cinnamatesnature, occurrence and dietary burden," Journal of the Science of Food and Agriculture, vol. 79, no. 3, pp. 362-372, 1999.

[42] M. R. Olthof, P. C. Hollman, and M. B. Katan, "Chlorogenic acid and caffeic acid are absorbed in humans," Journal of Nutrition, vol. 131, no. 1, pp. 66-71, 2001.

[43] G. H. Degen, P. Janning, P. Diel, and H. M. Bolt, "Estrogenic isoflavones in rodent diets," Toxicology Letters, vol. 128, no. 1-3, pp. 145-157, 2002.

[44] C. S. Yang and Z. Y. Wang, "Tea and cancer," Journal of the National Cancer Institute, vol. 85, no. 13, pp. 1038-1049, 1993.

[45] A. Farah, M. Monteiro, C. M. Donangelo, and S. Lafay, "Chlorogenic acids from green coffee extract are highly bioavailable in humans," Journal of Nutrition, vol. 138, no. 12, pp. 2309-2315, 2008.

[46] C. D. Gardner, L. M. Chatterjee, and A. A. Franke, "Effects of isoflavone supplements vs. soy foods on blood concentrations of genistein and daidzein in adults," Journal of Nutritional Biochemistry, vol. 20, no. 3, pp. 227-234, 2009.

[47] M. J. : Lee, P. Maliakal, L. Chen et al., "Pharmacokinetics of tea catechins after ingestion of green tea and (-)-epigallocatechin3-gallate by humans: formation of different metabolites and individual variability," Cancer Epidemiology, Biomarkers \& Prevention, vol. 11, no. 10, pp. 1025-1032, 2002.

[48] E. J. Kim, H. K. Shin, and J. H. Y. Park, "Genistein inhibits insulin-like growth factor-I receptor signaling in HT-29 human colon cancer cells: a possible mechanism of the growth inhibitory effect of genistein," Journal of Medicinal Food, vol. 8, no. 4, pp. 431-438, 2005.

[49] W. Qi, C. R. Weber, K. Wasland, and S. D. Savkovic, "Genistein inhibits proliferation of colon cancer cells by attenuating a negative effect of epidermal growth factor on tumor suppressor FOXO3 activity," BMC Cancer, vol. 11, p. 219, 2011.

[50] M. Kern, D. Fridrich, J. Reichert et al., "Limited stability in cell culture medium and hydrogen peroxide formation affect the growth inhibitory properties of delphinidin and its degradation product gallic acid," Molecular Nutrition and Food Research, vol. 51, no. 9, pp. 1163-1172, 2007.

[51] P. Bellion, M. Olk, F. Will et al., "Formation of hydrogen peroxide in cell culture media by apple polyphenols and its effect on antioxidant biomarkers in the colon cell line HT29," Molecular Nutrition \& Food Research, vol. 53, no. 10, pp. 12261236, 2009.

[52] L. H. Long, M. V. Clement, and B. Halliwell, "Artifacts in cell culture: rapid generation of hydrogen peroxide on addition of (-)-epigallocatechin, (-)-epigallocatechin gallate, $(+)$-catechin, and quercetin to commonly used cell culture media," Biochemical and Biophysical Research Communications, vol. 273, no. 1, pp. 50-53, 2000.

[53] K. S. Suh, S. Chon, S. Oh et al., "Prooxidative effects of green tea polyphenol (-)-epigallocatethin-3-gallate on the HIT-T15 pancreatic beta cell line," Cell Biology and Toxicology, vol. 26, no. 3, pp. 189-199, 2010.

[54] L. H. Long, D. Kirkland, J. Whitwell, and B. Halliwell, "Different cytotoxic and clastogenic effects of epigallocatechin gallate in various cell-culture media due to variable rates of its oxidation in the culture medium," Mutation Research, vol. 634, no. 1-2, pp. 177-183, 2007.

[55] M. López-Lázaro, J. M. Calderón-Montaño, E. Burgos-Morón, and C. A. Austin, "Green tea constituents (-)-epigallocatechin3-gallate (EGCG) and gallic acid induce topoisomerase Iand topoisomerase II-DNA complexes in cells mediated by pyrogallol-induced hydrogen peroxide," Mutagenesis, vol. 26, no. 4, pp. 489-498, 2011.

[56] I. A. Groh, A. T. Cartus, S. Vallicotti et al., "Genotoxic potential of methyleugenol and selected methyleugenol metabolites in cultured Chinese hamster V79 cells," Food and Function, vol. 3, no. 4, pp. 428-436, 2012.

[57] A. T. Cartus, K. Hermann, L. W. Weishaupt, W. Engst, H. Glatt, and D. Schrenk, "Metabolism of methyleugenol in liver microsomes and primary hepatocytes: pattern of metabolites, cytotoxicity, and DNA-adduct formation," Journal of Toxicological Sciences, vol. 129, no. 1, pp. 21-34, 2012.

[58] J. L. Burkey, J. M. Sauer, C. A. McQueen, and I. Glenn Sipes, "Cytotoxicity and genotoxicity of methyleugenol and related congeners-a mechanism of activation for methyleugenol," Mutation Research, vol. 453, no. 1, pp. 25-33, 2000. 
[59] G. Eot-Houllier, G. Fulcrand, L. Magnaghi-Jaulin, and C. Jaulin, "Histone deacetylase inhibitors and genomic instability," Cancer Letters, vol. 274, no. 2, pp. 169-176, 2009.

[60] P. Rajendran, B. Delage, W. M. Dashwood et al., "Histone deacetylase turnover and recovery in sulforaphane-treated colon cancer cells: competing actions of 14-3-3 and Pinl in HDAC3/SMRT corepressor complex dissociation/reassembly," Molecular Cancer, vol. 10, p. 68, 2011. 


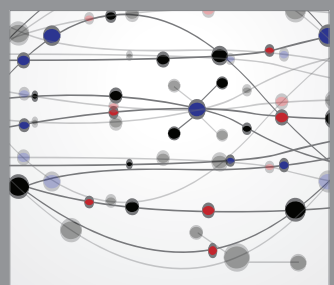

The Scientific World Journal
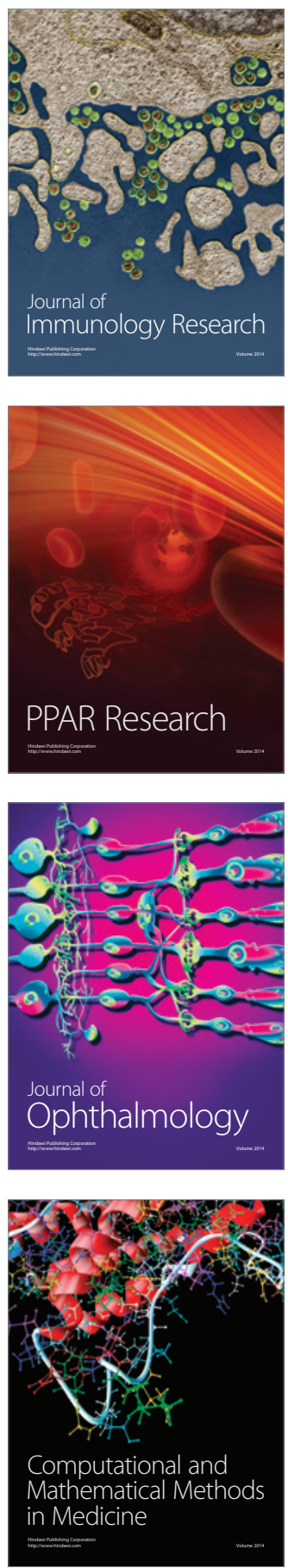

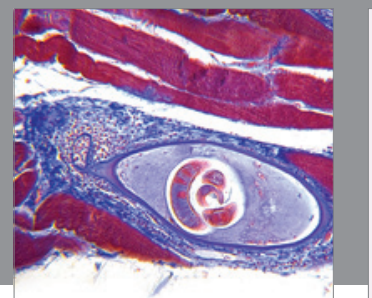

Gastroenterology

Research and Practice
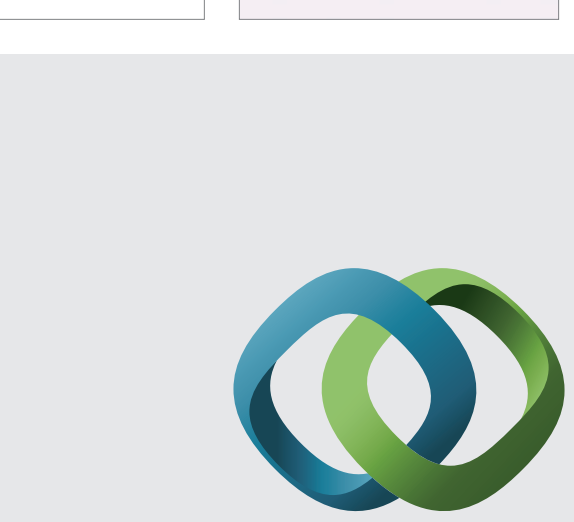

\section{Hindawi}

Submit your manuscripts at

http://www.hindawi.com
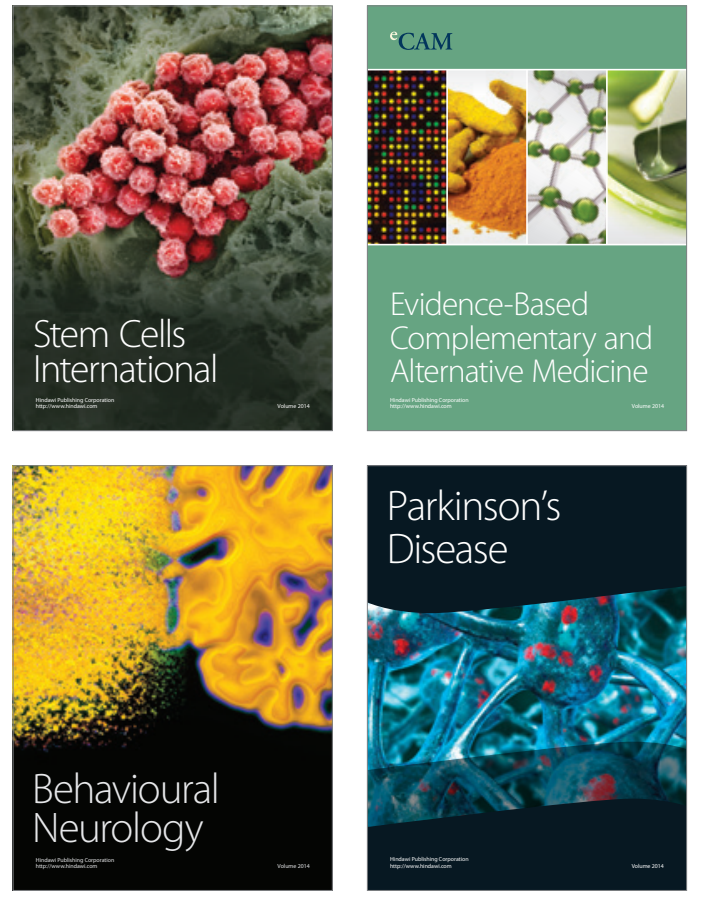
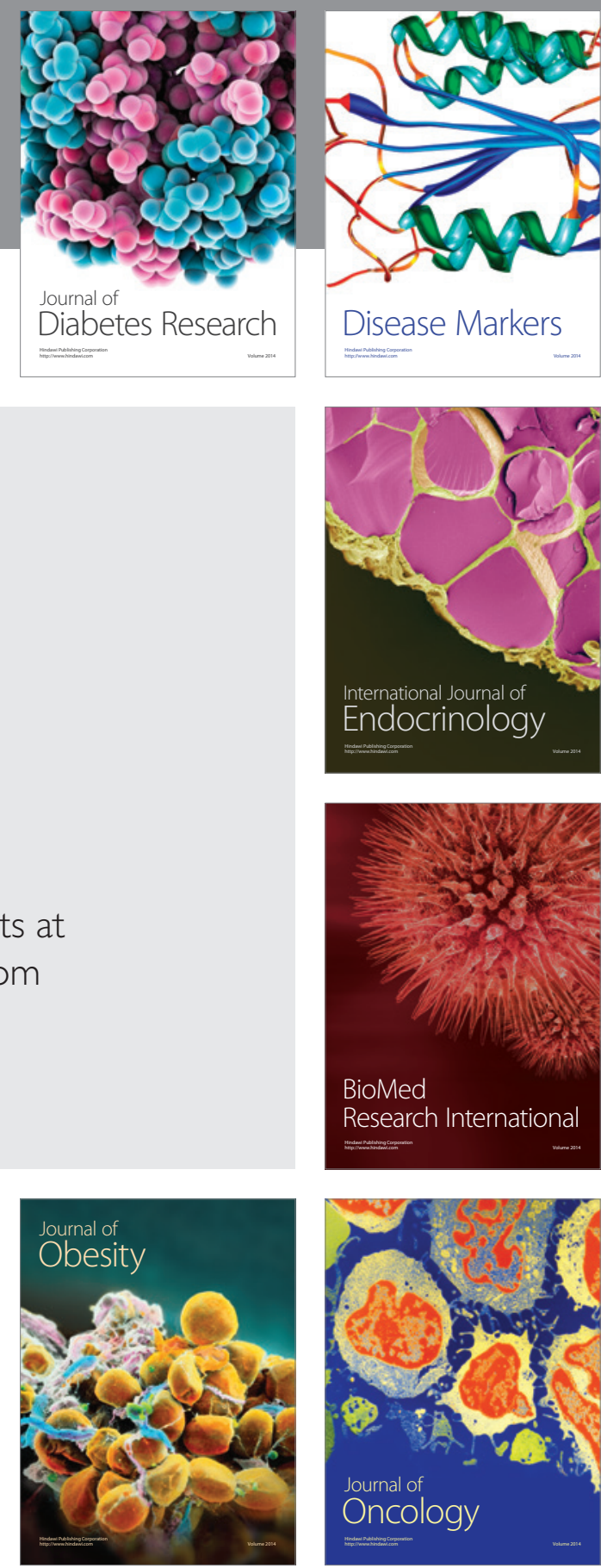

Disease Markers
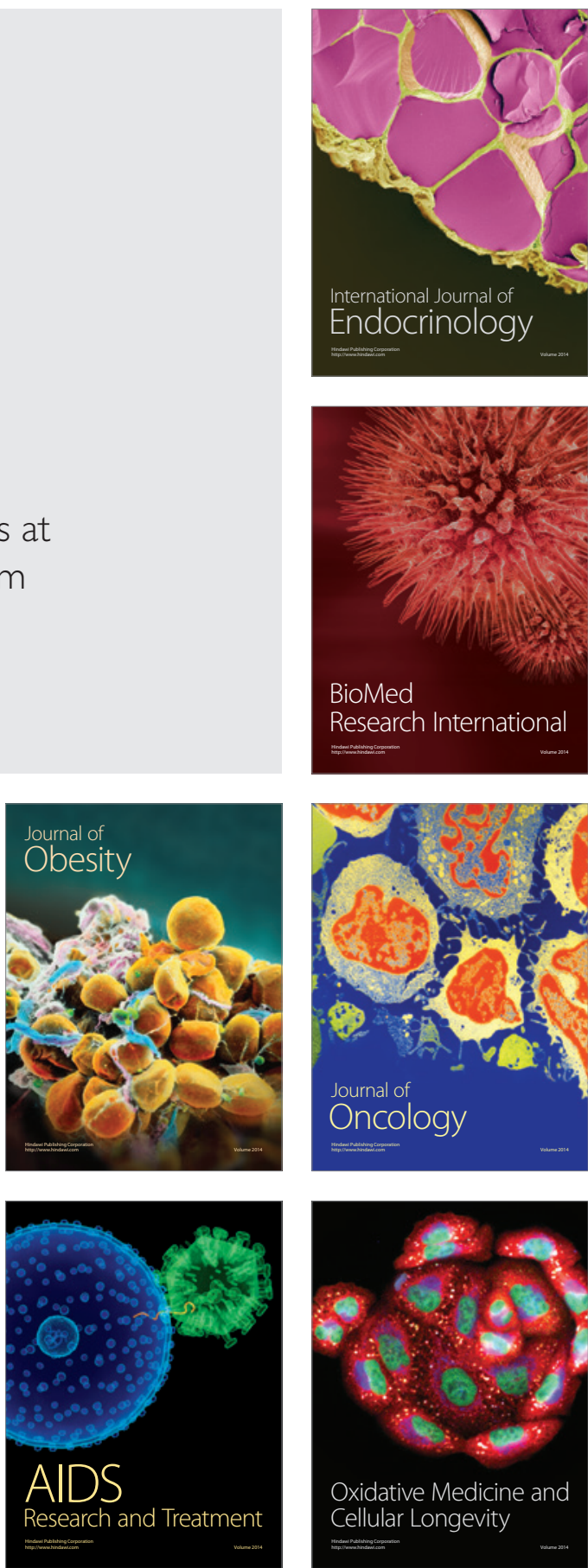